\title{
DEVELOPMENT AND PHARMACOKINETICS OF CURCUMIN LOADED BETA CAROTENE NANOPARTICLES IN RATS
}

\author{
RAVIKANTH CHINTHALA ${ }^{\mathrm{a}^{*}}$, SURYA SATYANARAYANA SINGH
}

aDepartment of Pharmacy, University College of Technology, Osmania University, Hyderabad 500007, Telangana, India, bDepartment of Biochemistry, University College of Science, Osmania University, Hyderabad 500007, Telangana, India

Email: ravikanth1717@gmail.com

Received: 07 Jun 2021, Revised and Accepted: 28 Jul 2021

\section{ABSTRACT}

Objective: The main objective of this research work is to improve the bioavailability of curcumin using beta carotene nanoparticles in experimental animals.

Methods: Curcumin-loaded beta carotene nanoparticles (NPs) have been prepared by emulsion-diffusion-evaporation method. Beta carotene and ethyl acetate were used to formulate NPs, and poly (vinyl alcohol) was used as a stabilizer. The emulsion diffusion evaporation method was used to prepare the nanoparticles and bioavailability and various pharmacokinetic parameters were compared with curcumin suspension in rats.

Results: The nanoparticles were successfully prepared using beta carotene and curcumin and the drug loading was almost $93 \%$ of the initial weight. Particle sizes were below $200 \mathrm{~nm}$ with negative zeta potentials. Comparing the pharmacokinetic parameters of curcumin loaded nanoparticles (C $\mathrm{Cmax}_{\text {, }}$ $\mathrm{T}_{\max }, \mathrm{K}_{\mathrm{el}}$, and AUC were $105 \mu \mathrm{g} / \mathrm{ml}, 2 \mathrm{~h}, 0.23 / \mathrm{h}$, and $\left.1629 \mu \mathrm{g} . \mathrm{hr} / \mathrm{ml}\right)$ with pure curcumin $\left(\mathrm{C}_{\max }, \mathrm{T}_{\max }, \mathrm{K}_{\mathrm{el}}\right.$ and AUC $16 \mu \mathrm{g} / \mathrm{ml}, 1 \mathrm{~h}, 0.275 / \mathrm{h}$ and 58 $\left.\mu \mathrm{g} . \mathrm{hr} / \mathrm{ml}\right)$ indicated a drastic improvement in bioavailability of curcumin.

Conclusion: The relative bioavailability was almost increased 30 times with beta carotene nanoparticles.

Keywords: Bio-availability, Curcumin, Beta carotene, Area under the curve, Overall elimination rate constant

(c) 2021 The Authors. Published by Innovare Academic Sciences Pvt Ltd. This is an open access article under the CC BY license (https://creativecommons.org/licenses/by/4.0/) DOI: https://dx.doi.org/10.22159/ijap.2021v13i5.42339. Journal homepage: https://innovareacademics.in/journals/index.php/ijap

\section{INTRODUCTION}

Research is continuously exploring new strategies to deliver active molecules with poor biopharmaceutical properties. There were strategies in existence, which increase the efficacy of existing drugs, reduce the adverse effects, and facilitate alternative routes of administration, and achieve site specificity [1]. Traditionally, efficient delivery has been achieved by physicochemical approaches design or use of excipients. The physicochemical approaches include salt forms, polymorphs, and chemical modifications. The design approaches include osmotic pumps, matrix or depots, and gels. The use of excipients is greatly influenced by formulation design. The application of a drug delivery tool in this process addresses one or more of the following questions related to the drug, physicochemical or metabolic instability, poor aqueous solubility or permeability, insufficient drug concentration in the target tissue, high volume of distribution, nontarget organ toxicity or rapid clearance from the body.

The focal point of product development studies is converging on means that impart such ability to the delivery system that can attain, even for otherwise poorly bioavailable compounds, sufficient concentrations across the intestinal barrier. The main challenges for drug delivery can be summarized as solubility, permeability, and drug targeting. Amongst the various novel drug delivery systems, nano-sized vehicles have attracted significant interest in this direction. The following section reviews the basics and applications of nanotechnology in drug delivery.

The timeline in drug delivery concerning nanotechnology can be viewed as drug delivery before and after the nanotechnology boom with the current transition period. Many of the presently known nanoparticulate drug delivery systems are produced with the previously existing technologies, for example, milling or emulsification techniques. Polymers like PLGA have taken the lead role in the development of nanoparticles [2]. Materials like lipids, inorganic materials, and proteins have also been used as carrier materials for the development of nanoparticles [3]. Most success for nanoparticulate drug delivery has been observed in cancer treatment. However, there are no known reports to the authors' knowledge that natural materials have been used as carrier materials. Among these natural materials, beta carotene is a potential candidate to be used as a carrier material, because of its physicochemical properties. Beta carotene is used as a supplement with antioxidant properties.

Beta carotene is a molecule that is available abundantly [4]. This has lipidic nature and is an antioxidant. Beta carotene was delivered as a nutritional supplement in many cases. However, no case was reported where the beta carotene is being used as a delivery vehicle. The present study explored to development of nanoparticles of beta carotene as an efficient drug delivery system. Beta carotene has no known toxicity and additional benefits like antioxidant effects that are desired in most disease conditions. Sometimes it has value as a food supplement and as alternative medicine in diseases like cancer and diabetes. It acts as a potent antioxidant by neutralizing the celldamaging free radicals and it helps converts food into energy. Several studies have revealed the potentials of this compound in prophylaxis and therapy of various disorders related to oxidative stress. All these reports illustrate the advantages of beta carotene as a suitable carrier material for advanced drug delivery systems like nanoparticles.

Curcumin is another natural material that has huge potential to be used as a drug [5]. However, its usage is limited because the molecule is poorly absorbed and results in poor bioavailability. There were previous reports of this molecule where the molecule has been delivered as nanoparticles and shown to have increased the bioavailability and efficacy in disease models.

\section{MATERIALS AND METHODS}

\section{Materials}

Curcumin and beta carotene were purchased from Yucca enterprises, India, and Hefei TNJ Chemical Industries Co., Ltd China, respectively. PLGA (MW 35-40 kDa) was purchased from Boehringer Ingelheim, (Germany). Ethyl acetate, EDTA, sucrose, mannitol, dextrose, trehalose, and polyvinyl alcohol were procured from Sigma-Aldrich. Purifier reverse osmosis water was used for all the experiments.

Preparation of blank and curcumin loaded beta carotene nanoparticles

Nanoparticles (NPs) were prepared by the emulsion-diffusionevaporation method, as previously reported by Devadasu et al., with 
slight modifications [6]. Beta carotene was dissolved in ethyl acetate to formulate NPs. The solubility of beta carotene in ethyl acetate is very high which is highly useful in developing NPs of beta carotene using emulsification methods. The following procedure was followed to prepare the NPs of beta carotene. The required amount of beta carotene is solubilized in dichloromethane or chloroform and emulsified in a stabilizer solution. The stabilizer used was poly (vinyl alcohol) which is used extensively in nanoparticle preparation. This emulsion will be diluted with water to facilitate the diffusion of dichloromethane or chloroform and to form nanosuspension.

Table 1: Formulations designed for experimentation

\begin{tabular}{|c|c|c|c|c|c|c|c|c|}
\hline Name of the ingredient & Blank 1 & Blank 2 & NP1 & NP2 & NP3 & NP4 & NP5 & NP6 \\
\hline Curcumin (mg) & 0 & 0 & 7.5 & 7.5 & 7.5 & 7.5 & 7.5 & 7.5 \\
\hline Beta Carotene (mg) & 0 & 50 & 0 & 10 & 20 & 30 & 40 & 50 \\
\hline PLGA (mg) & 50 & 0 & 50 & 40 & 30 & 20 & 10 & 0 \\
\hline Organic solvent (ml) & 2.5 & 2.5 & 2.5 & 2.5 & 2.5 & 2.5 & 2.5 & 2.5 \\
\hline Distilled water $(\mathrm{ml})$ & 5 & 5 & 5 & 5 & 5 & 5 & 5 & 5 \\
\hline
\end{tabular}

Briefly, curcumin and beta-carotene, and polymer were dissolved in $2.5 \mathrm{ml}$ of dichloromethane or chloroform under stirring for $30 \mathrm{~min}$. at $1200 \mathrm{rpm}$ (table 1). Further, this organic phase was added in a drop-wise manner to an aqueous phase containing a stabilizer to form an emulsion. This emulsion was stirred for $1 \mathrm{~h}$. followed by homogenization (Polytron PT4000; Polytron Kinematica, Switzerland) to reduce droplet size. The emulsion was then diluted with water to a large volume to effect solvent diffusion, resulting in nanoprecipitation. Curcumin loading was carried out at $10 \mathrm{mg}$ and $20 \mathrm{mg}$ per $50 \mathrm{mg}$ of beta carotene.

\section{Freeze drying of developed nanoparticles}

Freeze drying using an automated system (AdVantage, VirTis, USA) was adapted that was previously optimized for curcumin NPs. In brief, the conditions were as follows: condenser temperature $-60{ }^{\circ} \mathrm{C}$ and pressure applied during each step were 200 Torr. $2 \mathrm{~mm}$ of the nanoparticle suspension were filled in $5 \mathrm{ml}$ glass vials. The freezedrying process was optimized to get the NPs with good dispersibility. Various cryoprotectants and their concentrations were screened to get the free-flowing powder that can be easily dispersible. Mannitol, sucrose, and trehalose were used at 5\% concentration of NPs as cryoprotectants [7]. The freeze-dried samples were re-suspended in demineralized water and evaluated for size, nature of drug in NPs, surface charge, and morphology.

\section{Characterization of developed particles}

\section{Size, shape, surface morphology, and zeta potential}

Particle size and polydispersity index were measured by Photon Correlation Spectroscopy (PCS) using zetasizernanoZS (Malvern, UK) with the Malvern PCS software version 6.20. The zeta potential was measured by electrophoretic light scattering (ELS) mode using using zetasizer nano ZS. The data was recorded by maintained the instrument at $25^{\circ} \mathrm{C}$. Each value reported was an average of three independent measurements [6].

\section{Loading capacity and percentage yield}

Weight equivalent to one unit dose of the freshly prepared formulation was taken and diluted up to $10 \mathrm{ml}$ with chloroform. The obtained suspension was vortexed for $1 \mathrm{~h}$ and centrifuged for 45 min at 6,000 rpm (5804R, Eppendorf, Germany). The supernatant was separated and filtered through a $0.2 \mu \mathrm{m}$ filter. The filtrate was diluted using chloroform and analyzed at $421 \mathrm{~nm}$ using a UV spectrophotometer (Systronics 2203 Smart, India). A UV calibration curve was developed at the same wavelength was used for the analysis. The formulations formulated without curcumin were treated similarly and used as a control for the measurements. The assay was repeated 3 times using different preparations. Encapsulation efficiency was calculated using the formula [7]:

$$
\text { Encapsulationefficiency }=\frac{\text { Weightofcurcumininnanoparticles }}{\text { weightofcurcuminadded }} \times 100
$$

The percentage of production yield was calculated from the weight of dried NPs recovered from each batch and the sum of the initial weight of starting materials. The percentage yield was calculated using the following formula [7]:

\section{Percentageyield $=\frac{\text { PracticalmassNanoparticles }}{\text { Theoriticalmass }(\text { Polymer }+ \text { drug })} \times 100$}

\section{In vitro drug release studies}

The release pattern of curcumin from NPs was carried out using the dialysis membrane method. Curcumin nanosuspension equivalent to the unit dose of curcumin was filled in a dialysis bag. The bag was then dipped into $100 \mathrm{ml}$ of phosphate buffer 7.4 (containing 10\% Tween 80 ) at $37{ }^{\circ} \mathrm{C}$ under magnetic stirring at a speed of $100 \mathrm{rpm}$. The drug-containing dialysis bag (molecular weight cut off 12 to 14 $\mathrm{kDa}$, pore size $2.4 \mathrm{~nm}$ ) was dialyzed against the receiver compartment. To determine the curcumin diffused through the dialysis bag, $2 \mathrm{ml}$ samples were withdrawn at regular time intervals from the receiver solution and the same amount of fresh receiver solution was added to maintain the volume constant. Curcumin concentrations in the released samples were measured spectrophotometrically at $421 \mathrm{~nm}$ using a UV spectrophotometer [8]. The release experiments were carried out in triplicate. The control NPs without curcumin were treated similarly and used as blanks for the measurements.

\section{In vivo pharmacokinetic study}

The in vivo performances of the optimized formulations are evaluated by pharmacokinetic studies on healthy Wistar rats (obtained from Mahaveera Enterprises, No. 203, Harsha Homes, 2-2185/55/E, Hyderabad-500013, Telangana, India). The animals are housed in metallic cages with free access to move and provided standard laboratory diet and water in the central animal house. The research protocol of animal experimentation is approved by the Institutional Animal Ethics Committee.

Based on the evaluation of in vitro dissolution, PSD, and zeta potential behavior, optimized formulations are selected to carry out in vivo performance in comparison with the pure drug suspension. The dose of each drug is calculated using the below formula, where $K_{m}$ values of rats and humans are taken to be 7 and 37 .

$$
\text { Humanequivalentdose }\left(\frac{\mathrm{mg}}{\mathrm{kg}}\right)=\frac{\text { AnimaldosexAnimalKmvlaue }}{\text { HumanKmvalue }}
$$

Eighteen healthy rats with a bodyweight range of 200-250 g were selected through physical examination. Animals were randomly divided into three groups consisting of two in each group. Each group received a single dose of different formulations in random order and the scheme of administration of the treatments as Group A-Pure drug solution, Group B-NP1, and Group C-NP6. The animals were fasted overnight before administering the dose. After collecting the zero-hour blood sample (blank), a standardized diet was given in the morning. After each time point, $0.5 \mathrm{ml}$ venous blood samples were collected from the tail vein of each animal in microcentrifuge tubes containing EDTA. Blood Samples were collected at 0, 0.25, 0.5, $1,2,4,8,12,18$ and $24 \mathrm{~h}$. Plasma was immediately separated by centrifugation at $5000 \mathrm{rpm}$ for $30 \mathrm{~min}$ from the blood samples and stored in frozen conditions at $-20^{\circ} \mathrm{C}$ with appropriate labeling of the subject code number, study date, and collection time before analysis. The concentration of drugs in plasma samples was measured by the HPLC [7]. 
Pharmacokinetic parameters such as peak plasma concentration $\left(\mathrm{C}_{\max }\right)$, time at which $\mathrm{C}_{\max }$ occurred $\left(\mathrm{T}_{\max }\right)$, area under the curve (AUC), elimination rate constant $\left(\mathrm{K}_{\mathrm{el}}\right)$, biological half-life $\left(\mathrm{t}_{1 / 2}\right)$, absorption rate constant $\left(\mathrm{K}_{\mathrm{a}}\right)$ and mean residence time (MRT) were calculated in each case using the data by KineticaTM 2000 software (Inna Phase Corporation, U. S. A) using the non-compartmental approach. Percent relative bioavailability was determined as follows.

$$
\% \text { Relative bioavailability }=\frac{\mathrm{AUC}_{[0 \text {-xo]test }}}{\mathrm{AUC}_{[0-\mathrm{ox}] \text { reference }}} \times 100
$$

\section{RESULTS}

Development of blank and curcumin loaded beta carotene nanoparticles

All the developed nanoparticles showed particle sizes less than $200 \mathrm{~nm}$ (table 2). Blank nanoparticles showed lower sizes than the drug-loaded nanoparticles. NP6 showed almost similar size to the blank nanoparticles suggesting the compact nature of the beta carotene nanoparticles. The zeta potential is negative in all cases and the entrapment efficiency of curcumin resulted to be over $90 \%$ in the case of NP6.

Table 2: Characterization of nanoparticles

\begin{tabular}{|c|c|c|c|c|}
\hline Formulation code & Particle size (nm) & PDI & Zeta potential (mV) & Entrapment efficiency (\%) \\
\hline Blank 1 & $100 \pm 3.2$ & $0.120 \pm 0.023$ & $-21.3 \pm 2.8$ & - \\
\hline Blank 2 & $110.1 \pm 2.4$ & $0.120 \pm 0.013$ & $-21.5 \pm 2.6$ & - \\
\hline NP1 & $145.5 \pm 5.5$ & $0.178 \pm 0.015$ & $-21.2 \pm 2.5$ & $63.45 \pm 3.56$ \\
\hline NP2 & $135.3 \pm 3.5$ & $0.234 \pm 0.016$ & $-25.6 \pm 3.4$ & $62.56 \pm 2.56$ \\
\hline NP3 & $148.5 \pm 5.7$ & $0.565 \pm 0.012$ & $-26.4 \pm 3.6$ & $52.43 \pm 5.26$ \\
\hline NP4 & $158.7 \pm 3.8$ & $0.225 \pm 0.014$ & $-21.4 \pm 2.6$ & $53.36 \pm 2.56$ \\
\hline NP5 & $184.5 \pm 5.2$ & $0.135 \pm 0.020$ & $-22.5 \pm 2.1$ & $75.65 \pm 3.58$ \\
\hline NP6 & $116.2 \pm 5.7$ & $0.115 \pm 0.023$ & $-28.5 \pm 3.4$ & $93.56 \pm 2.56$ \\
\hline
\end{tabular}

$\mathrm{n}=3$; values are expressed as mean $\pm \mathrm{SD}$

\section{Freeze drying of developed nanoparticles}

The freeze-dried nanoparticles retained properties similar to the initial nanoparticles with trehalose. The size seems to be slightly increased and the zeta potential decreased slightly after the freezedrying process.

\section{In vitro drug release studies}

In vitro release of curcumin from NPs formulation is illustrated in fig. 1. The data obtained under sink conditions indicated the sustained release of the drug over a $24 \mathrm{~h}$ study period. All the nanoparticles showed sustained drug release for at least $15 \mathrm{~h}$ to $24 \mathrm{~h}$. The sustained release is shown to be more in the case of NP4 where the PLGA and beta carotene are in almost equal ratios.

\section{In vivo pharmacokinetic study}

The pharmacokinetic study showed bioavailability improvement by the nanoparticles in comparison to the pure drug formulation used in the study. The beta carotene nanoparticles showed the highest bioavailability in comparison to the pure drug formulation and the PLGA nanoparticles. The plasma concentration-time profile of various formulations was shown in fig. 2. Various pharmacokinetic properties have been shown in table 4 .

Table 3: Characteristics of the freeze-dried nanoparticles

\begin{tabular}{llll}
\hline Formulation code & Particle size (nm) & & Zeta potential (mV) \\
\cline { 2 - 4 } & Before & After & Before \\
\hline Blank 1 & $100 \pm 3.2$ & $110 \pm 5.2$ & $-21.3 \pm 2.8$ \\
Blank 2 & $110.1 \pm 2.4$ & $119.5 \pm 2.9$ & $-21.5 \pm 2.6$ \\
NP1 & $145.5 \pm 5.5$ & $165.5 \pm 7.5$ & $-21.2 \pm 2.5$ \\
NP2 & $135.3 \pm 3.5$ & $154.4 \pm 3.1$ & $-25.6 \pm 3.4$ \\
NP3 & $148.5 \pm 5.7$ & $178.6 \pm 7.9$ & $-26.4 \pm 3.6$ \\
NP4 & $158.7 \pm 3.8$ & $167.4 \pm 2.5$ & $-21.4 \pm 2.6$ \\
NP5 & $184.5 \pm 5.2$ & $200.2 \pm 3.2$ & $-22.5 \pm 2.1$ \\
NP6 & $116.2 \pm 5.7$ & $126.5 \pm 6.9$ & $-28.5 \pm 3.4$ \\
\hline
\end{tabular}

$\mathrm{n}=3$; values are expressed as mean $\pm \mathrm{SD}$

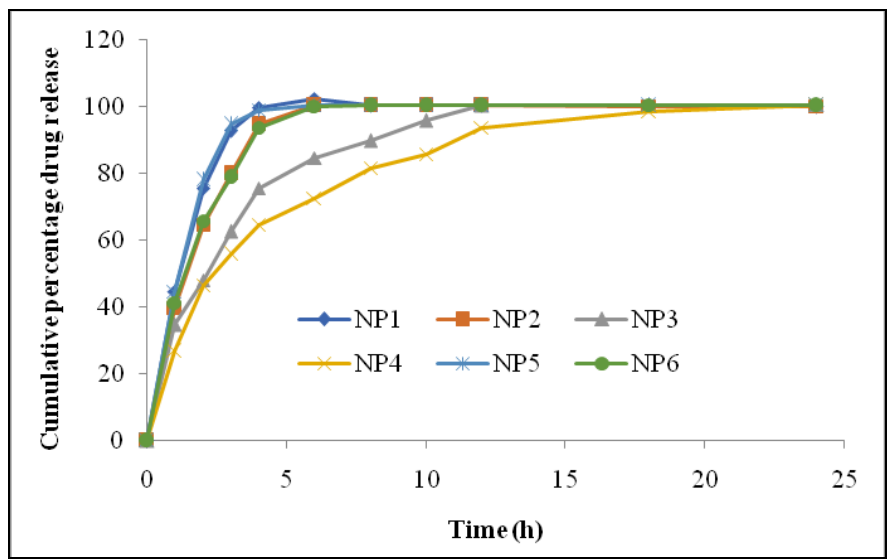

Fig. 1: In vitro drug release profiles of curcumin from the nanoparticles 


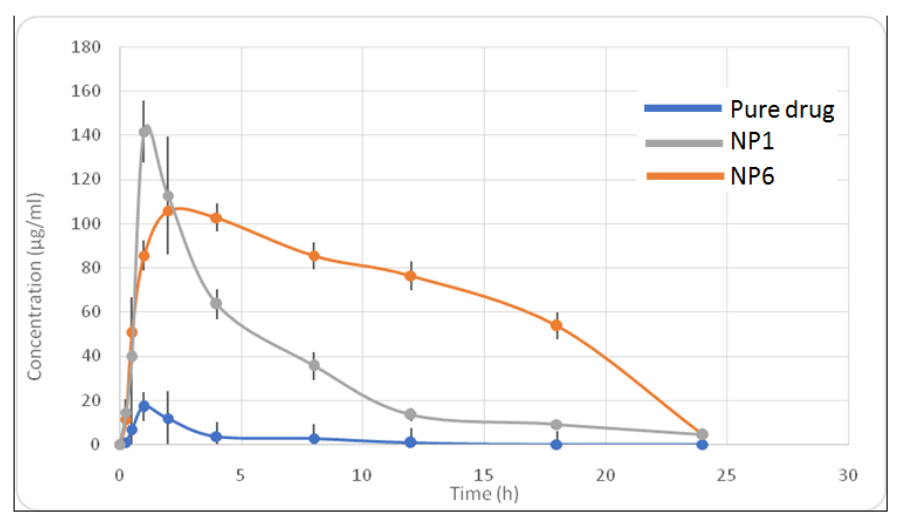

Fig. 2: Plasma concentration-time data of nanoparticles

Table 4: In vivo pharmacokinetic parameters

\begin{tabular}{|c|c|c|c|c|}
\hline Parameter & Unit & PD & NP1 & NP6 \\
\hline Lambda_z & $1 / \mathrm{h}$ & 0.27 & 0.15 & 0.23 \\
\hline $\mathrm{t}_{1 / 2}$ & $\mathrm{~h}$ & 2.51 & 4.56 & 2.93 \\
\hline $\mathrm{T}_{\max }$ & $\mathrm{h}$ & 1 & 1 & 2 \\
\hline $\mathrm{C}_{\max }$ & $\mu \mathrm{g} / \mathrm{ml}$ & 16.96 & 141.48 & 105.75 \\
\hline $\mathrm{T}_{\text {lag }}$ & $\mathrm{h}$ & 0 & 0 & 0 \\
\hline $\mathrm{C}_{\text {last_obs }}^{\circ} / \mathrm{C}_{\max }$ & & 0.04 & 0.02 & 0.04 \\
\hline $\mathrm{AUC}_{0-\mathrm{t}}$ & $\mu \mathrm{g} . \mathrm{hr} / \mathrm{ml}$ & 56.30 & 758.16 & 1610.44 \\
\hline AUC $_{0 \text {-inf_obs }}$ & $\mu \mathrm{g} . \mathrm{hr} / \mathrm{ml}$ & 58.63 & 785.71 & 1629.35 \\
\hline AUC ${ }_{0-t / 0 \text {-infobs }}$ & & 0.96 & 0.96 & 0.98 \\
\hline AUMC 0 -inf_obs & $\mu \mathrm{g} . \mathrm{hr}^{2} / \mathrm{ml}$ & 234.26 & 5256.98 & 15576.12 \\
\hline $\mathrm{MRT}_{0 \text {-inf_obs }}$ & $\mathrm{h}$ & 3.99 & 6.69 & 9.55 \\
\hline $\mathrm{Vz} / \mathrm{F}_{\text {-obs }}$ & $(\mathrm{mg} / \mathrm{kg}) /(\mu \mathrm{g} / \mathrm{ml})$ & 0.46 & 0.06 & 0.01 \\
\hline $\mathrm{Cl} / \mathrm{F}_{\text {obs }}$ & $(\mathrm{mg} / \mathrm{kg}) /(\mu \mathrm{g} / \mathrm{ml}) / \mathrm{h}$ & 0.12 & 0.0095 & 0.0046 \\
\hline Relative BA & & & 1340 & 2778 \\
\hline
\end{tabular}

PD-Pure drug curcumin; NP1-Curcumin loaded PLGA nanoparticles; NP6-Curcumin loaded beta carotene nanoparticles; data are average of two animal data.

\section{DISCUSSION}

The developed nanoparticles showed larger sizes with the drug loading [9]. This is due to the mass increment that has happened during the drug loading. However, the sizes were still below $200 \mathrm{~nm}$ in all cases. The drug entrapment efficiency was very good in all cases with over $50 \%$. However, the highest entrapment efficiency was achieved in the case of beta carotene nanoparticles. The entrapment efficiency is important in the sense that the drug and the macromolecule have good physical interaction and the drug release would be slower [10]. The lipophilic nature of the beta carotene might have helped in achieving higher entrapment efficiency. The zeta potential is negative due to the nature of the stabilizer polymer used in the study [11].

The freeze-drying of nanoparticles is important to have a good shelf life before the usage of the drug-loaded nanoparticles. The lyoprotectants sucrose, mannitol, and trehalose were used in the study. However, trehalose showed good stability concerning minimal increments in size and minimal reduction in the zeta potential. These results are in corroboration with the published literature report $[7,12]$.

In vitro release of curcumin from NPs formulation is illustrated in fig. 1. Since curcumin is a hydrophobic drug, tween 80 was used in the receiver solution. In vitro release data obtained under sink conditions indicated the sustained release of the drug over a $24 \mathrm{~h}$ study period. The initial fast release (burst effect) could be attributed to the presence of a small fraction of unentrapped drugs or drugs embedded near the NPs surface. Other factors contributing to a fast release were large surface area, high diffusion coefficient (small molecular size), low matrix viscosity, and short diffusion distance of the drug. The slow-release was mainly due to the low diffusion of drug molecules through the lipid or polymer matrix of the NPs and hindering effects by the surrounding matrix shell. Slow drug release contributes to maintaining effective therapeutic drug concentrations. The large surface area of NPs, the high diffusion coefficient of the entrapped drug, the viscosity of the lipid matrix as well as the presence of surfactants adsorbed and incorporated in the surface during the production process were some important factors affecting the drug release from NPs. The magnitude of burst release from NP's depends on various formulation and processing parameters. An increase in burst effect could be promoted by a higher surfactant concentration.

Good interpretation of the in vitro and in vivo performance of the dosage form is a fundamental objective in pharmaceutical product development. In vitro studies may not give complete information about in vivo performance, due to poor correlation exists between in vitro and in vivo performance due to various unpredictable physiological factors that affect drug release and absorption, particularly in the case of an oral controlled drug delivery system [13].

From the results of the pharmacokinetic study, it was observed that the plasma concentration of the optimized formulation is extended up to $24 \mathrm{~h}$. It was also observed that Mean residence time is extended up to $9.5 \mathrm{~h}$ with beta carotene nanoparticles and whereas for $6.69 \mathrm{~h}$ with PLGA nanoparticles. The relative bioavailability of the optimized formulation is increased by 27.78 times with beta carotene nanoparticles and 13.40 times with PLGA nanoparticles. The bioavailability improvement could be due to the improved absorption of the beta carotene nanoparticles as these nanoparticles seem to be more lipophilic because of the beta carotene.

\section{CONCLUSION}

In conclusion, we can say that beta carotene is a good matrix material for the entrapment of drugs. The sustained release was 
equivalent to the PLGA nanoparticles in vitro and in vivo bioavailability increment was also almost double the PLGA nanoparticles. This warrants the use of beta carotene nanoparticles uses in the drug delivery through nanoparticles as a matrix material. Beta carotene seemed to be as good as PLGA in providing sustained release and increments in bioavailability. Being a natural material it can be explored with other drugs as well for the studied benefits.

\section{FUNDING}

Nil

\section{AUTHORS CONTRIBUTIONS}

All authors have contributed equally.

\section{CONFLICTS OF INTERESTS}

Declared none

\section{REFERENCES}

1. Nayak AK, Ahmad SA, Beg S, Ara TJ, Hasnain MS. Drug delivery: present, past, and future of medicine. In: Inamuddin, Asiri AM, Mohammad A. (eds) Applications of nanocomposite materials in drug delivery. Woodhead Publishing Series in Biomaterials, Elsevier Inc; 2018. p. 255-82.

2. Ahmad R, Srivastava S, Ghosh S, Khare SK. Phytochemical delivery through nanocarriers: a review. Colloid Surface B 2021;197:111389.

3. Devadasu VR, Bhardwaj V, Kumar MR. Can controversial nanotechnology promise drug delivery? Chem Rev 2013;113:1686-735.

4. Marinoa T, Casellab P, Sangiorgioc P, Verardic A, Ferrarod A, Hristoforoud E, et al. Natural beta-carotene: a microalgae derivate for nutraceutical applications. Chem Eng 2020;79:1.

5. Sharifi Rad J, Rayess YE, Rizk AA, Sadaka C, Zgheib R, Zam W, et al. Turmeric and its major compound curcumin on health: bioactive effects and safety profiles for food, pharmaceutical, biotechnological and medicinal applications. Front Pharmacol 202;11:1021.

6. Devadasu VR, Wadsworth RM, Kumar MR. Protective effects of nanoparticulate coenzyme Q 10 and curcumin on inflammatory markers and lipid metabolism in streptozotocin-induced diabetic rats: a possible remedy to diabetic complications. Drug Delivery Transl Res 2011;1:448-55.

7. Shaikh J, Ankola DD, Beniwal V, Singh D, Kumar MR. Nanoparticle encapsulation improves oral bioavailability of curcumin by at least 9-fold when compared to curcumin administered with piperine as absorption enhancer. Eur J Pharm Sci 2009;37:223-30.

8. Rapalli VK, Kaul V, Gorantla S, Waghule T, Dubey SK, Pandey $\mathrm{MM}$, et al. UV Spectrophotometric method for characterization of curcumin loaded nanostructured lipid nanocarriers in simulated conditions: method development, in vitro and exvivo applications in topical delivery. Spectrochim Acta Part A 2020;224:117392.

9. Lala RR, Shinde AS, Nandvikar NY. Solid lipid nanoparticles: a promising approach for combinational drug therapy in cancer. Int J Appl Pharm 2018;10:17-22.

10. Jogala SA, Chinnala KM, Aukunuru JI. Novel subcutaneous sustained release nanoparticles encapsulating low molecular weight heparin (LMWH): preparation, characterization and evaluation. Int J Pharm Pharm Sci 2016;8:264-8.

11. Gupta M. Synergistic anti-cancer effects of natural products and their mode of action. Asian J Pharm Clin Res 2021;14:15-21.

12. Shelat PR, Mandowara VK, Gupta DG, Patel SH. Formulation of curcuminoid loaded solid lipid nanoparticles in order to improve oral bioavailability. Int J Pharm Pharm Sci 2015;7:278-82.

13. Sapavatu SN, Chinthala R, Jadi RK. An overview on pharmacokinetics of polymeric nanoparticles intended for oral delivery. J Young Pharm 2020;12:187-9. 